\title{
Damage Identification of Ancient Timber Structure Based on Autocorrelation Function
}

\author{
Yanfang Hou $\mathbb{D}^{1,2}$ Weibing ${ }^{1,},{ }^{1}$ Xin Wang, ${ }^{3}$ Tingting Hou, ${ }^{4}$ and Congli Sun ${ }^{1}$ \\ ${ }^{1}$ School of Civil Engineering, Xi'an University of Architecture and Technology, Xi'an 710055, China \\ ${ }^{2}$ School of Civil Engineering, Shaanxi Polytechnic Institute, Xianyang 712000, China \\ ${ }^{3}$ School of Civil Engineering, Tianshui Normal University, Tianshui 741001, China \\ ${ }^{4}$ School of Management, Xi'an University of Architecture and Technology, Xi'an 710055, China \\ Correspondence should be addressed to Yanfang Hou; houyf@xauat.edu.cn
}

Received 21 October 2020; Revised 11 June 2021; Accepted 27 June 2021; Published 7 July 2021

Academic Editor: Xuemei Liu

Copyright $\odot 2021$ Yanfang Hou et al. This is an open access article distributed under the Creative Commons Attribution License, which permits unrestricted use, distribution, and reproduction in any medium, provided the original work is properly cited.

\begin{abstract}
A damage location method for the autocorrelation peak value change rate based on the vibration response of a random vibration structure is established. To calculate the autocorrelation function of the vibration response of each measurement point, we transformed the maximum values into an autocorrelation peak vector. Under a good condition, the autocorrelation peak vector has a fixed shape; hence, it can be used as a basis for structural damage identification. The two adjacent measurement points with the largest change corresponding to the two nodes of the damage unit and the damage location are determined to calculate the change rate of the autocorrelation peak values between damaged and intact structures. When the degree of damage is $5 \%$, the autocorrelation peak value change rate of the acceleration response on the two nodes of the damage unit is significantly greater than that of the other points, which can accurately determine the damage location, indicating that the damage location index constructed has good damage sensitivity. The damage location index can determine a single damage, as well as a double damage. The antinoise capability of the damage location index gradually improves with an increase in the degree of damage. At $45 \%$ degree of damage and signal-to-noise ratio (SNR) of $0 \mathrm{~dB}$, the damage location index can still accurately determine the damage location, which has good antinoise interference capability. The Xi'an Bell Tower is used as a case study, and the feasibility of this method is verified, which provides a new method for the study of damage location of ancient timber structures.
\end{abstract}

\section{Introduction}

Chinese ancient structures, precious cultural heritage, and important parts of human civilization objectively and faithfully reflect the development and features of history, preserving many historical materials, which cannot be recorded in a written language. Therefore, they are known as the "three-dimensional textbooks" and "ready-made museum." Weather-beaten ancient structures are more valuable not only because they have survived thousands of years, but they are also the remains of history. Once they are destroyed, they can never be recovered.

Chinese ancient structures, which are mainly made of wood, can adjust measurements to local conditions and local materials, taking wooden technology to the extreme. For example, the main hall of the Nanchan Temple in Mount Wutai has an extremely strict distribution of wooden components. There are no redundant structures or bracket sets between the columns. In terms of structure, it has reached the state of "to add a point is redundant, to subtract a point is to lack" [1]. Numerous mortise-tenon joints have been found at the Hemudu site in Yuyao, Zhejiang, which reflects the long history of wood structure technology in China. However, ease of burning and deterioration of the wood have led to the collapse and disappearance of Chinese ancient wooden structures.

Consequently, studies have been initiated on damage identification methods of ancient wooden structures by scholars worldwide. Wang and Yang [2] applied a vibration response sensitivity damage identification method to 
identify three different damage states of beams and columns of ancient Tibetan wooden structures. The results show that this method can accurately identify damage to the beams and columns of the ancient Tibetan wooden structure. Wang et al. [3-6] carried out a finite-element simulation of ancient wooden structures under random excitation using wavelet packet energy spectrum and wavelet packet curvature difference method to identify and locate damage to wooden structures. Fan [7] established a finite-element model of a wooden frame and adopted a damage identification method combining the wavelet packet analysis method and stochastic resonance theory to evaluate the damage location and degree of damage of the structure. Choi [8] adopted a model-based damage detection method to identify the locations of common damage defects in wood and estimate the degree of damage. Hu and Afzal [9] proposed a new statistical algorithm, which was validated by the numerical simulation of different degrees of damage and damage locations of wooden beams.

Many scholars have studied damage identification methods based on correlation functions. Mohammad used the cross-correlation damage index to determine the damage locations in the length of continuous deck bridges, and a comparison of the obtained analytical results with the experimental results showed that the proposed methods can determine the damage locations with appropriate accuracy for different damage scenarios [10]. Morgantini and Betti presented a structural damage assessment method that relies on a cross-correlation-based damage-sensitive feature, which is extracted from the dynamic response measured at different locations within a structure [11]. Li and Huang proposed an approach to identify structural states from eigenvectors constructed using cross-correlation functions. The method was first applied to damage detection of a numerical model of a jacket platform in the Bohai Sea [12]. Li et al. carried out an experimental study of structural damage detection by applying the cross-correlation function amplitude vector (CorV) of dynamic strain under varying environmental temperatures; the study verified that, under white noise excitation, CorV is only related to natural frequencies, mode shapes, and damping ratios of structures. A laboratory experimental investigation based on an end-fixed steel beam showed that CorV can be used for structural damage detection [13]. Lin and Fajri proposed a structural health monitoring (SHM) system based on detrended fluctuation analysis (DFA) and detrended cross-correlation analysis (DCCA); the performance of the SHM system was verified using a four-layer numerical model [14]. Huo et al. combined cross-correlation function amplitude (CCFA) with a support vector machine (SVM) for damage detection of a bone structure [15]. Zhang et al. [16-18] proposed a new approach to locate damage using the autocorrelation function of vibration response signals and performed detailed investigation of the damage index based on the autocorrelation function to detect the damage of a structure under white noise excitation.

At present, studies on damage identification methods for ancient wooden structures mainly focused on the components of the structures [19-21]. However, very few studies have investigated the overall building structures. In addition, existing damage identification methods are often affected by measurement noise and have low antinoise capabilities. In this study, the Xi'an Bell Tower was used as a case study, and a finite-element model of the upper part of the bell tower was established. The damage identification and location index of the autocorrelation peak change rate were constructed based on the principle and property of the autocorrelation function. The two adjacent test points with the largest change rate of the autocorrelation peak value before and after the damage correspond to the two nodes of the damage element, and the damage location of the structure was realized. The damage sensitivity and antinoise capability of the positioning index were analyzed, which provides a new method for damage identification and positioning of ancient wooden structures.

\section{Basic Theory of Autocorrelation Function [22-24]}

2.1. Correlation and Autocorrelation Functions. Correlation is an important measure of the relationship between two or more random variables. Suppose that $x(t)$ and $y(t)$ are two waveforms corresponding to two different signals in a random vibration process. To measure the similarity between the two waveforms, one can be moved relative to the other. When the two waveforms reach a certain degree of similarity, it can be said that the two random variables $x(t)$ and $y(t)$ are related.

For a random vibration process $x(t)$, its autocorrelation indicates the similarity between signal $x(t)$ and the delay signal $x(t+\tau)$. In other words, the autocorrelation function describes the correlation degree of the random signal $x(t)$ at any two different times $t$ and $t+\tau$, which is defined as the average value of the product of $x(t)$ and $x(t+\tau)$, namely, $E$ $[x(t) x(t+\tau)]$. If the waveform $x(t)$ is divided into $N$ equally spaced discrete values $x_{1}, x_{2}, \ldots, x_{N}$, then

$$
E[x(t) x(t+\tau)]=\frac{1}{N} \sum_{i=1}^{N} x_{i}(t) x_{i}(t+\tau)
$$

In the above equation, $\tau$ is the moving value of the time coordinate, not time, and it can be either positive or negative.

If the waveform is continuous, it should be discretized, the number of sampling points is $N$, and the time interval is $\Delta t$, then

$$
N-1=\frac{T}{\Delta t}
$$

If the value of $\Delta t$ is small, or $N \longrightarrow \infty, \mathrm{d} t$ can be used to represent $\Delta t$, then equation (2) becomes

$$
\frac{1}{N}=\frac{\Delta t}{T+\Delta t}=\frac{\mathrm{d} t}{T}
$$

By substituting equation (3) into (1) and changing the sum into an integral, we obtain 


$$
\phi_{x x}(\tau)=\lim _{T \longrightarrow \infty} \frac{1}{T} \int_{0}^{T} x(t) x(t+\tau) \mathrm{d} t .
$$

In the equation, $T$ is the time history of the selected waveform and $\tau$ is the time difference between the two groups of vibration data, which is called the lag.

The size of $\varphi(\tau)$ was quantified to measure the similarity between the two groups of vibration data. $\varphi(\tau)$ is related not only to the characteristics of the signal, but also to the time interval $\tau$. If $\varphi(\tau)$ reaches the maximum value at $\tau=\tau_{i}$, it means that they are the most similar, that is, the most relevant degree.

2.2. Autocorrelation Peak Vector. According to the concept of the relevant function, the smaller the time interval $\tau$, the closer the relationship between $x(t+\tau)$ and $x(t)$, and the greater the $\varphi_{x x}(\tau)$ value. As the value of $\tau$ increases, $x(t+\tau)$ and $x(t)$ can reach a state of irrelevance, where $\varphi_{x x}(\tau)$ tends to a minimum, or zero. Therefore, the autocorrelation function has the following properties:

(1) When $\tau$ is very large, the autocorrelation function of a random variable with an average value of 0 approaches 0 , namely,

$$
\lim _{\tau \longrightarrow 0} \phi_{x x}(\tau)=\phi_{x x}( \pm \infty)=0 .
$$

This shows that there is no correlation between $x(t+\tau)$ and $x(t)$.

(2) When $\tau=0$, the autocorrelation function of a random variable with an average value of zero is maximized and is equal to the mean square value of the signal, namely,

$$
\phi_{x x}(0)=E\left[x^{2}(t)\right]=D[x] .
$$

(3) The autocorrelation function $\varphi_{x x}(\tau)$ will never be greater than its initial value when $\tau$ takes any value, namely,

$$
\left|\phi_{x x}(\tau)\right| \leq \phi_{x x}(0)
$$

This is because when $\tau=0, x(t+\tau)$ is related to $x(t)$. The correlation between two states of a random process cannot be greater than that between the state at the same point and itself; that is, the signal is strongly correlated with itself, and the correlation is the largest. Hence, the maximum number of $\varphi_{x x}(\tau)$ is $\varphi_{x x}(0)$.

For a structure with random vibration, if the dynamic response (acceleration, velocity, displacement, etc.) of $N$ measurement points is simultaneously measured, then the maximum value of the autocorrelation function of the dynamic response of each measurement point is $\varphi_{x x}(0)=\delta_{i i}$. All the maximum values constitute the autocorrelation peak vector, denoted as

$$
A=\left[\delta_{11}, \delta_{22}, \ldots, \delta_{n n}\right] .
$$

When an engineering structure is damaged, the dynamic characteristics and dynamic response of the structure will change. The autocorrelation peak is calculated based on the dynamic response of the structure. Therefore, when the structure is damaged, the autocorrelation peak also changes. The degree of change of each element value before and after the damage can be measured by the peak value change rate as follows:

$$
\Delta_{i i}=\frac{\delta_{i i}^{d}-\delta_{i i}^{u}}{\delta_{i i}^{u}} \times 100 \%,
$$

where $\delta_{i i}^{u}$ is the peak value of the autocorrelation function of the dynamic response of each measurement point of the intact structure, $\delta_{i i}^{d}$ is the peak value of the autocorrelation function of the dynamic response at each measurement point of the damaged structure, and $\Delta_{i i}$ is the rate of change of the dynamic response of the autocorrelation peak at each measurement point before and after structural damage.

The greater the change rate of the autocorrelation peak value of the dynamic response, the greater the degree of damage of the structure. Therefore, the autocorrelation peak change rate can be used to construct the damage identification and location index to identify structural damage.

The maximum value of the peak change rate is normalized as follows:

$$
\Delta_{i i}^{*}=\frac{\Delta_{i i}}{\max \left(\Delta_{i i}\right)} .
$$

\section{Overview and Establishment of Finite- Element Model of the Xi'an Bell Tower $[25,26]$}

3.1. Overview of the Xi'an Bell Tower. Built during the Hongwu period of the Ming Dynasty (1384), the Xi'an Bell Tower (see Figure 1) is one of the largest, grandest and bestpreserved Ming architectures in China. It is located at the intersection of the East, West, South, and North four main streets in the city center of Xi'an; it is the landmark building of Xi'an, known as the "Pearl of the Ancient City." The bell tower covers an area of approximately $1,377.6 \mathrm{~m}^{2}$ and is composed of three parts: the platform, tower, and roof. The lower platform is a cuboid with an underside length of $35.5 \mathrm{~m}$ and a height of $8.6 \mathrm{~m}$. The interior of the high platform is composed of plain packed earth layer compaction and there are arch holes in the middle of all sides with a height and width of $6 \mathrm{~m}$ and $6 \mathrm{~m}$, respectively. The main body of the building is a $27.4 \mathrm{~m}$ two-story wooden structure with triple eaves. The plane is a square, surrounded by cloisters. The bell tower is a timber frame structure with four central columns and 12 surrounding columns. The lower end of the columns is placed on a rammed earth foundation through the plinth, and the upper end extends to the roof.

The Xi'an Bell Tower is similar to the frame structure, whose wall does not bear weight but only plays the role of enclosure and separation of the space. The columns are connected by beams with a high span ratio through mortise and tenon joints, which together with the wall form an antilateral force system, enhancing the integrity of the bell tower structure. The plane of the bell tower structure is 


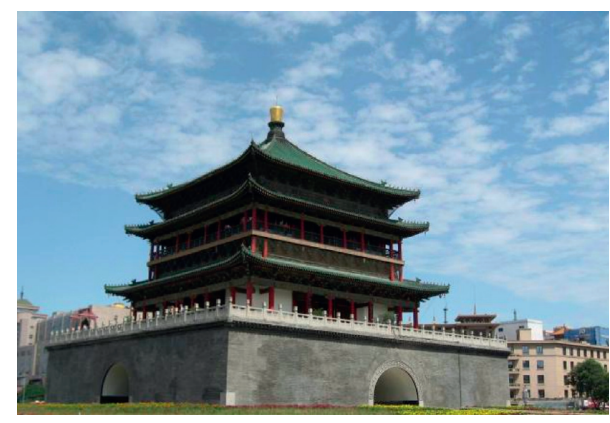

Figure 1: The Xi'an Bell Tower.

symmetrical, and the distribution of mass and stiffness is even. This arrangement not only prevents stress concentration due to the excessive internal force of the corner column but also makes the dynamic characteristics of all directions on the building plane roughly consistent; therefore, the torsion effect of the structure caused by the deviation between the mass center and the stiff center is reduced.

In this study, the finite-element model of the upper frame was established based on the structural characteristics of the Xi'an Bell Tower. A damage identification method based on the autocorrelation function of random vibration structures is proposed; a damage identification and location index of the autocorrelation peak change rate was constructed and the damage location of the structure was realized. This resulted in a new method for damage identification and positioning of ancient wooden structures.

\subsection{Establishment of Finite-Element Model. The timber} frame structure of the upper part of the bell tower is composed of 12 pillars $\mathrm{C}-1$ on the periphery and four pillars $\mathrm{C}-2$ at the center, as well as timber beams B-1, B-2, and B-3. A schematic diagram of the bell tower is shown in Figure 2. The section size and material parameters of each member are listed in Table 1.

The parameters of the wood material are based on the measured data in reference [28], as listed in Table 2.

One notable feature of ancient Chinese wooden structures is that beams and columns are connected by mortise and tenon joints, unlike steel and reinforced concrete structures. In a mortise and tenon joint, the tenon has a certain length, and there is a certain gap between the mortise and tenon. Therefore, the connection is neither rigid nor hinge, but a semirigid connection [29-33]. The energy dissipation caused by friction and sliding between the mortise and tenon is an important contributor to the good seismic performance of ancient wooden structures [34]. Han studied and demonstrated the stiffness of the mortise and tenon joints of wooden structures and obtained the stiffness value, as presented in Table 3 [35].

A finite-element software program, ANSYS, was used to build the wooden frame model. The coupling function of the joints and the stiffness of the spring element were used to simulate the semirigid characteristic of the mortise and tenon joints. The mortise and tenon joint was realized to

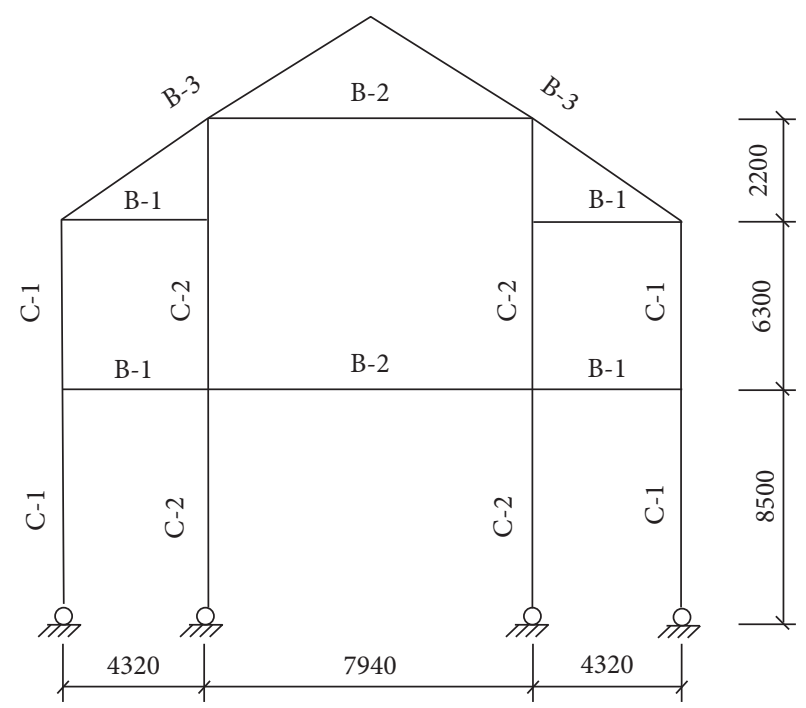

Figure 2: Diagram of the Xi'an Bell Tower [27].

TABle 1: Section size of beam and column [27].

\begin{tabular}{lccc}
\hline Column component & C-1 & C-2 & - \\
\hline Cross-sectional diameter $(\mathrm{mm})$ & 500 & 700 & - \\
Beam component & B-1 & B-2 & B-3 \\
Cross-sectional size $(\mathrm{mm} \times \mathrm{mm})$ & $300 \times 700$ & $300 \times 800$ & $200 \times 300$ \\
\hline
\end{tabular}

TABle 2: Material parameters [28].

\begin{tabular}{lccc}
\hline Material & Elasticity moduli $(\mathrm{MPa})$ & $\begin{array}{c}\text { Density } \\
\left(\mathrm{kg} / \mathrm{m}^{-3}\right)\end{array}$ & Poisson's ratio \\
\hline Timber & 8307.3 & 410 & 0.25 \\
\hline
\end{tabular}

TABLE 3: Stiffness value of mortise and tenon joints.

\begin{tabular}{lccc}
\hline Name & $K_{x}=K_{z}(\mathrm{~N} / \mathrm{m})$ & $K_{y}(\mathrm{~N} / \mathrm{m})$ & $R_{X}=R_{Y}=R_{Z}(\mathrm{~N} \cdot \mathrm{m})$ \\
\hline Side span & $1.71 \times 10^{7}$ & $2.07683 \times 10^{8}$ & $6.244 \times 10^{8}$ \\
\hline
\end{tabular}

establish several overlapping finite-element nodes at the connecting position of the beam and column, representing the ends of each beam and column of the mortise and tenon joint. The spring element was applied only at the position where the beam and column are connected, and no spring element was applied between the posts. The spring element connects the column end node (1) with beam end nodes (2), (3), (4), and (5). Six spring elements were used to simulate the end nodes of the column and beam, and the spring stiffness parameters of each degree-of-freedom direction of the beam and column were set to realize the mortise and tenon joint, as shown in Figure 3.

Three-dimensional elastic elements were used to simulate the wooden beams and columns. The roof mass was applied to the top of the column in the form of concentrated mass to consider the influence of the inertia force of the roof mass, and the mass element was used to simulate a large roof. The finite-element model of the timber frame structure in the upper part of the bell tower is shown in Figure 4. 


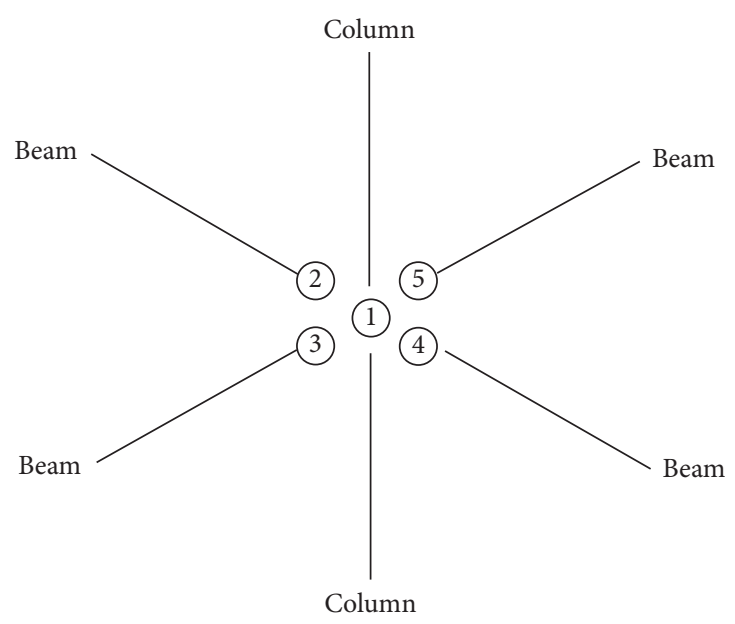

Figure 3: Mortise-tenon joint between beam and column.

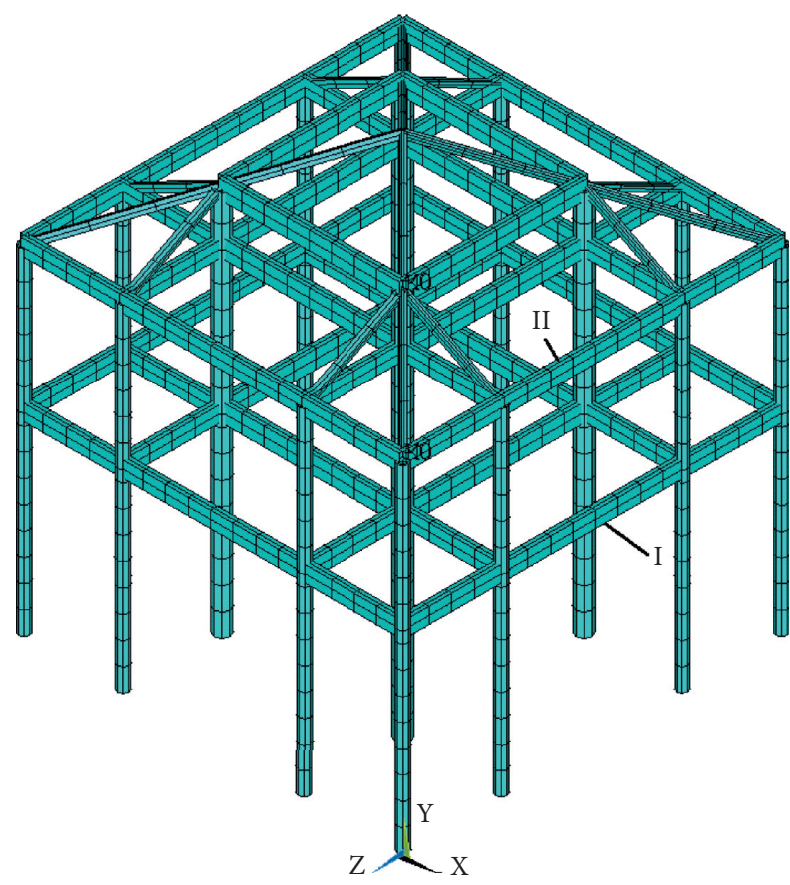

Figure 4: Wooden structure of the Xi'an Bell Tower.

\section{Damage Localization and Identification of the Xi'an Bell Tower}

4.1. Intrinsic Form of Autocorrelation Peak Vector. The central spans of the first and second floors of the timber frame of the bell tower, namely, beams I and II in Figure 4, were selected for analysis. The number of elements of beam I is 230 to 235 and the corresponding number of nodes is 800 to 806 , whereas the number of elements of beam II is 454 to 459 and the corresponding number of nodes is 1,048 to 1,054, as shown in Figure 5.

The Xi'an Bell Tower is located at the intersection of the East, West, South, and North streets, and the surrounding traffic environment is complicated. Lines 2 and 6 of the Xi'an Subway meet at the bottom of the Bell Tower. The Bell Tower
Station of Line 2 is approximately $60 \mathrm{~m}$ south of the bell tower. To analyze the impact of subway operation on the bell tower, Zhao [26] calculated the acting load of Xi'an Subway Line 2 and Line 6 during single line operation using the empirical analysis model of train load and obtained the load values under different running speeds.

When $V_{1}=20 \mathrm{~km} / \mathrm{h}, \quad F(t)=70,000+31.95$ sin 3.49 $t+91.3 \sin 17.44 t+292.1 \sin 69.8 t$.

When $V_{2}=40 \mathrm{~km} / \mathrm{h}, \quad F(t)=70,000+127.8$ sin 6.98 $t+365.2 \sin 34.89 t+1168.5 \sin 139.56 t$.

$V_{1}$ and $V_{2}$ were applied to plinth node 501 as random excitation sample 1 and random excitation sample 2, respectively. The excitation time is $t=12 \mathrm{~s}$ and the time step is $\Delta t=0.01 \mathrm{~s}$.

The $X$-direction horizontal acceleration responses of each node on beams I and beam II were extracted. Taking node 803 of beam I and node 1048 of beam II as examples, the autocorrelation value of node acceleration was calculated, as shown in Figure 6.

It can be observed from the diagram that the autocorrelation function of the acceleration response of nodes 803 and 1048 is largest when $\tau=0$ because the signal correlated with itself and the degree of correlation is highest.

Taking beam I as an example, the autocorrelation function of each node on the beam was calculated at subway loads of $V_{1}=20 \mathrm{~km} / \mathrm{h}$ and $V_{2}=40 \mathrm{~km} / \mathrm{h}$. The maximum value was transformed into an autocorrelation peak vector, and the peak value vectors of the autocorrelation functions of each node of the wooden frame intact structure under random excitations 1 and 2 were recorded as $A_{1}$ and $A_{2}$, respectively, as shown in Figure 7.

It can be observed from the figure that the peak value curves of the two autocorrelation functions under two different random excitations are almost identical. This shows that, for a random vibration structure, the autocorrelation peak vector of the dynamic response of each measurement point has a fixed shape when the structure is intact. Therefore, the change in the peak value of the autocorrelation function of the dynamic response of the random vibration structure can be used to identify the damage to the structure.

4.2. Single Damage Location Analysis. According to the intrinsic morphological characteristics of an intact structure, when the structure is damaged, the peak curve of the autocorrelation function fluctuates, reducing the correlation between the autocorrelation peak curves of the damaged structure and intact structure.

Structural damage can be simulated by reducing the stiffness of the elements. The specific method is as follows: two types of materials with different elasticity moduli are defined, the intact value and the one with a certain percentage reduction, corresponding to the intact and the damaged structures, respectively. Damage simulation of the structure can be realized by replacing a certain element of the beam with a reduced elastic modulus. Select beam I as the research object, when each element of 230 to 235 on the beam is damaged by $10 \%$, the rate of change of the 


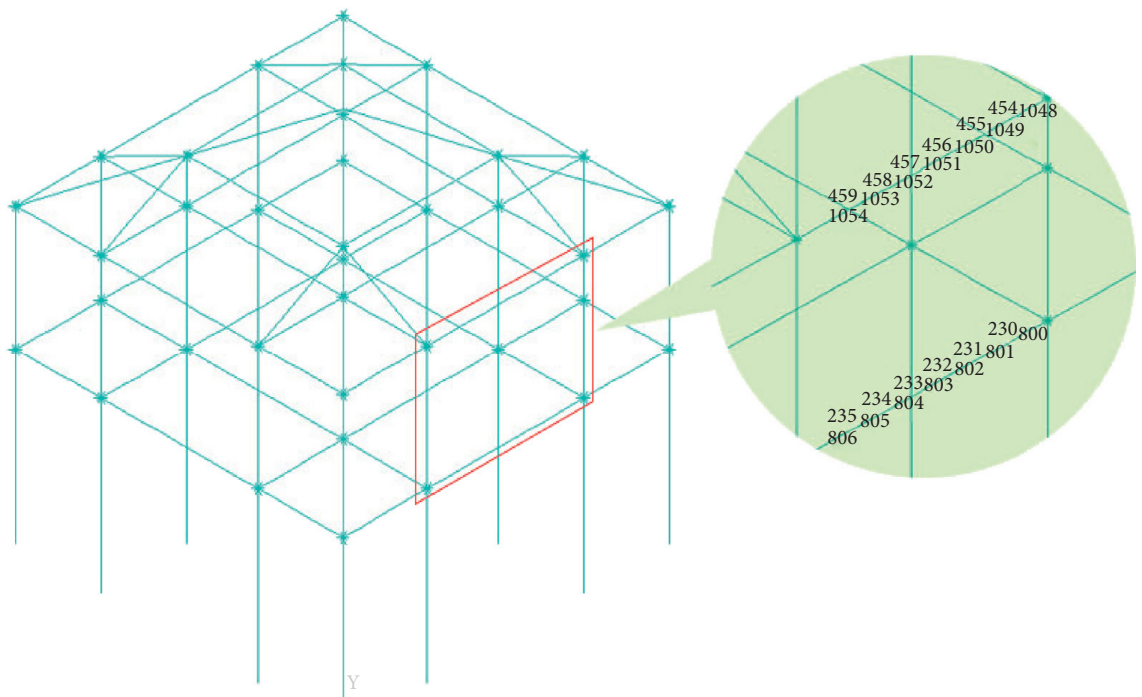

Figure 5: Number of nodes and elements of beams I and II.

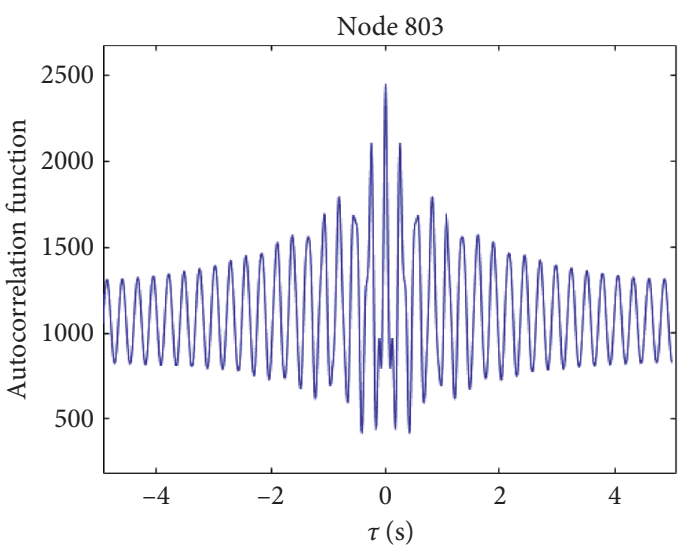

(a)

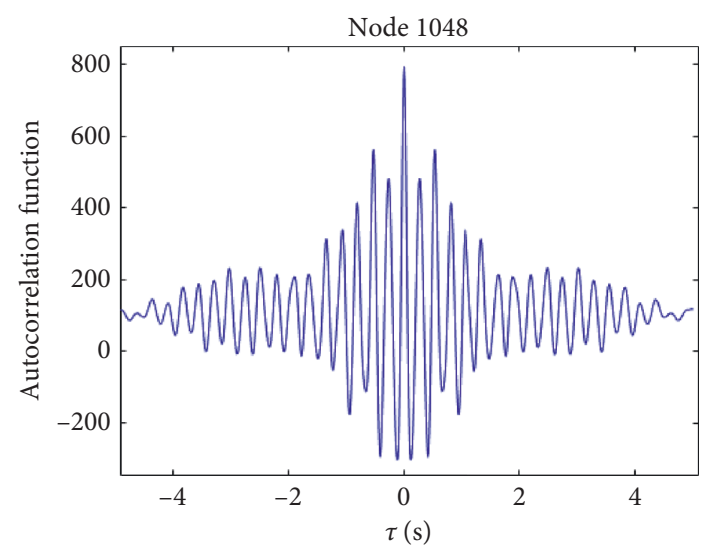

(b)

FIGURE 6: Normalized autocorrelation values of (a) node 803 and (b) node 1048.

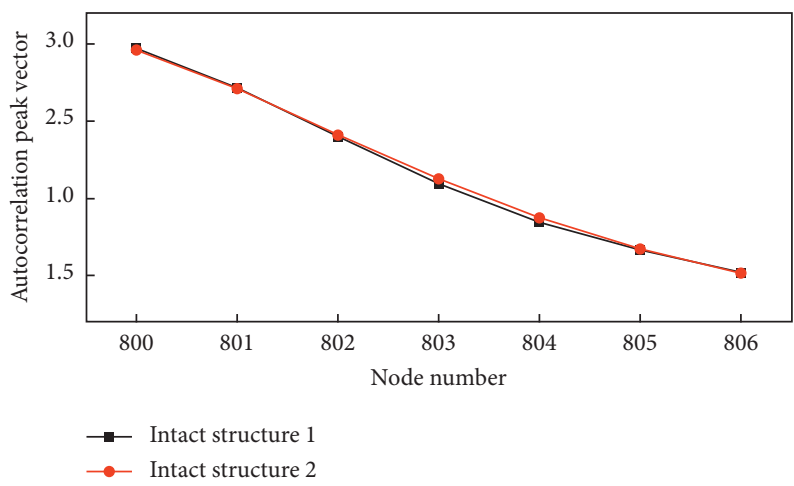

FIgURE 7: Inherent form of the intact structures.

autocorrelation peak value of the acceleration response of each node between the damaged structure and the intact structure is shown in Figure 8.
It can be observed from the figure that when damage occurs to a certain element on the beam, the peak rate of change of the two nodes corresponding to the element is the 


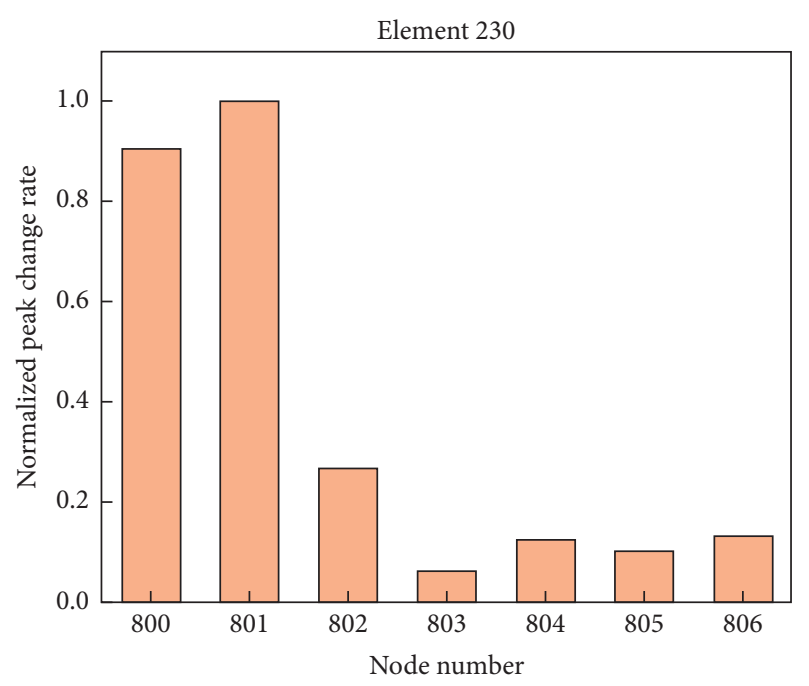

(a)

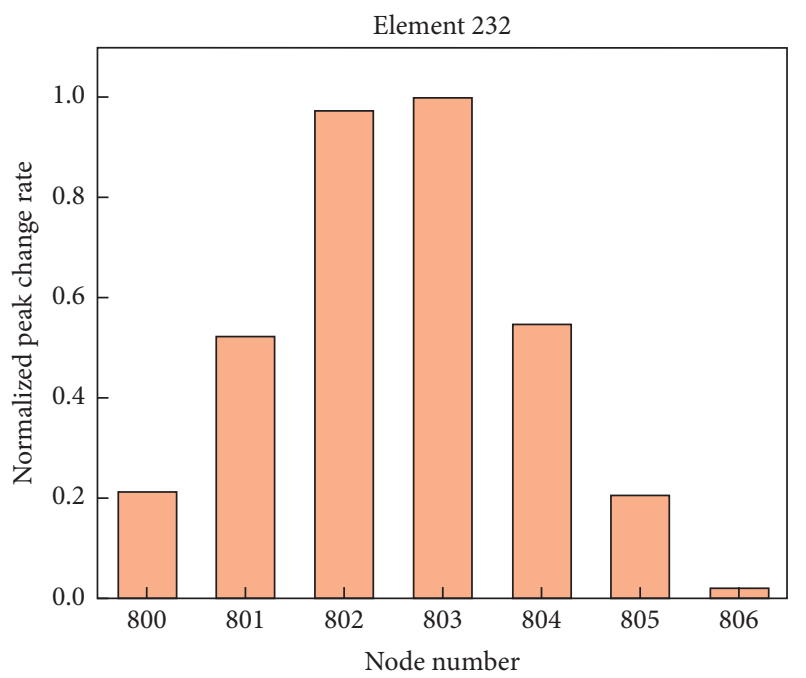

(c)

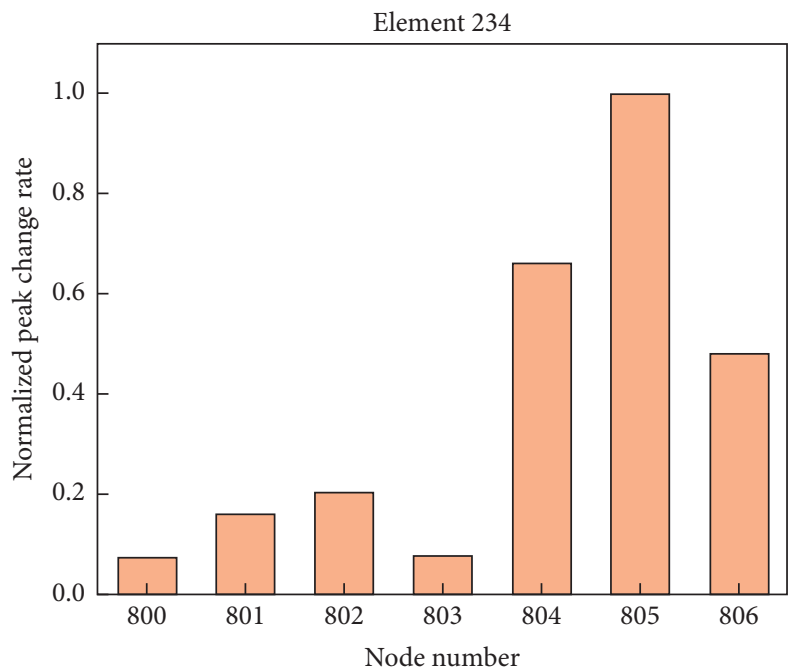

(e)

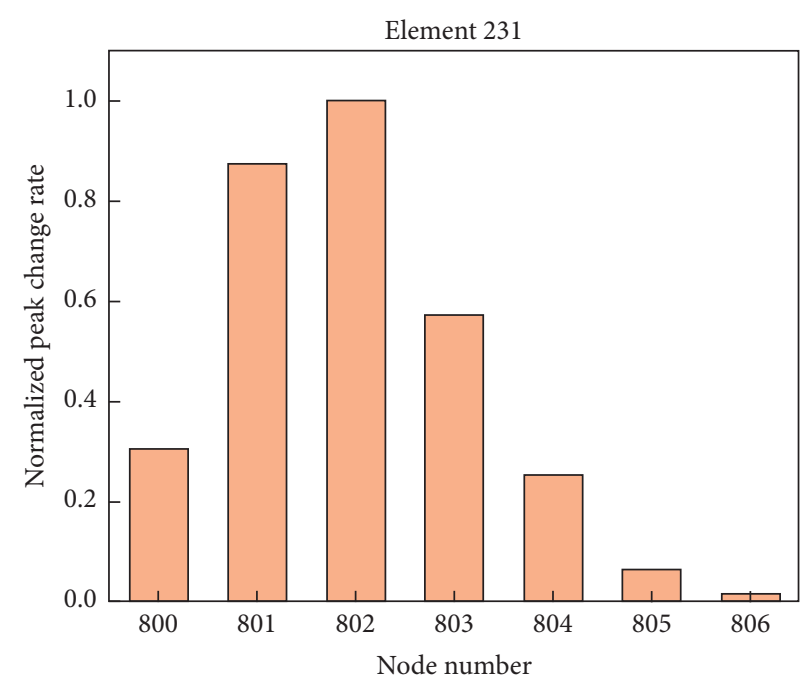

(b)

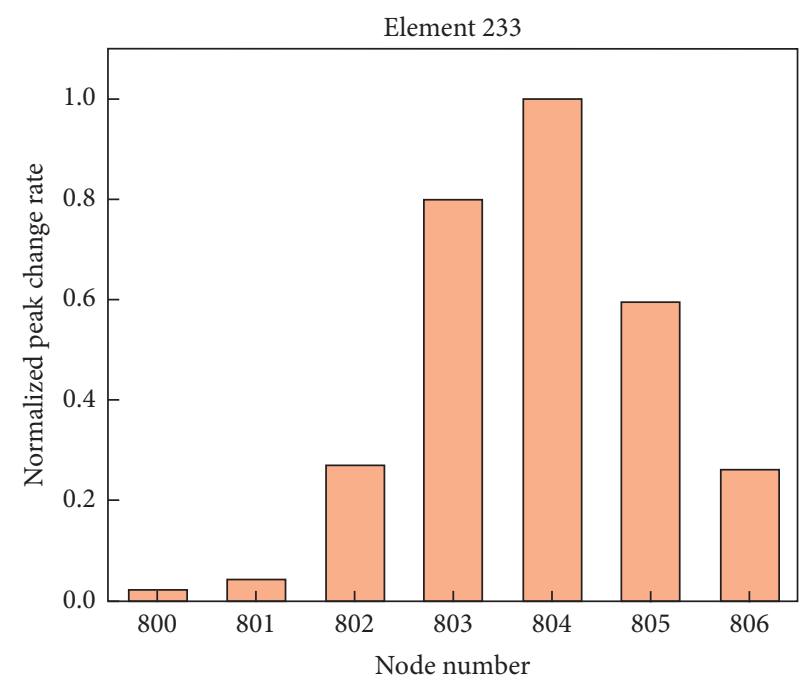

(d)

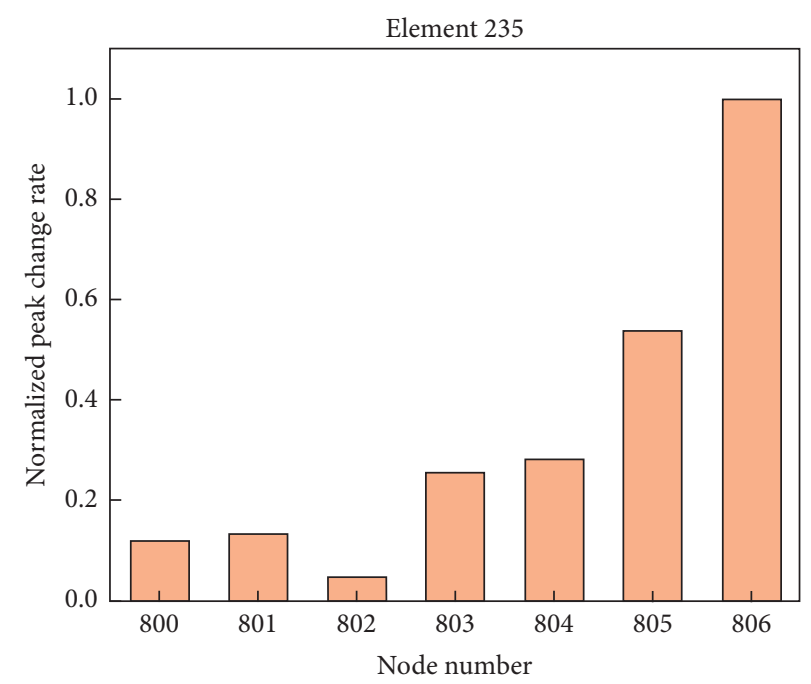

(f)

Figure 8: The peak rate of change between the damaged structure and the intact structure. 
TABle 4: Double damage conditions.

\begin{tabular}{lcccr}
\hline Damage conditions & Condition 1 & Condition 2 & Condition 3 & Condition 4 \\
\hline Damage elements & $230 / 459$ & $231 / 456$ & $232 / 456$ & $232 / 458$ \\
Corresponding nodes & $800,801 / 1053,1054$ & $801,802 / 1050,1051$ & $802,803 / 1050,1051$ & $802,803 / 1052,1053$
\end{tabular}

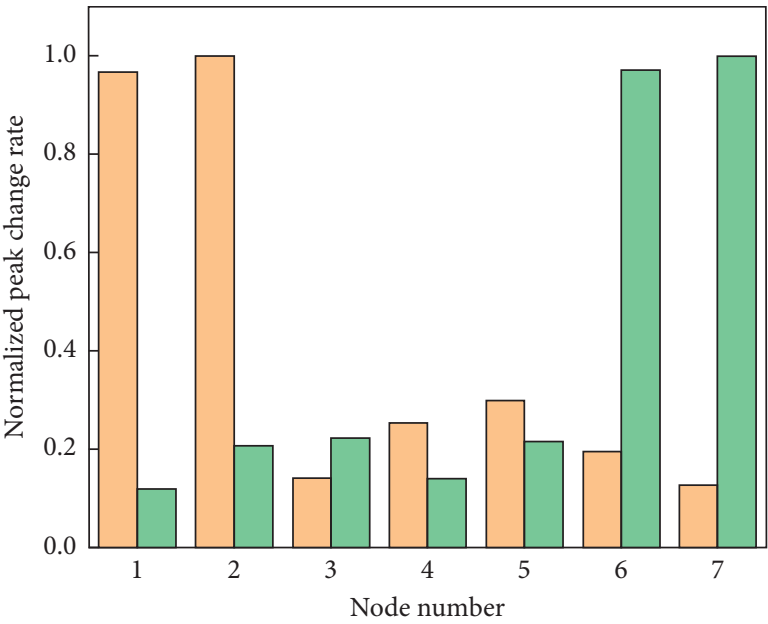

Beam I

$\square$ Beam II

(a)

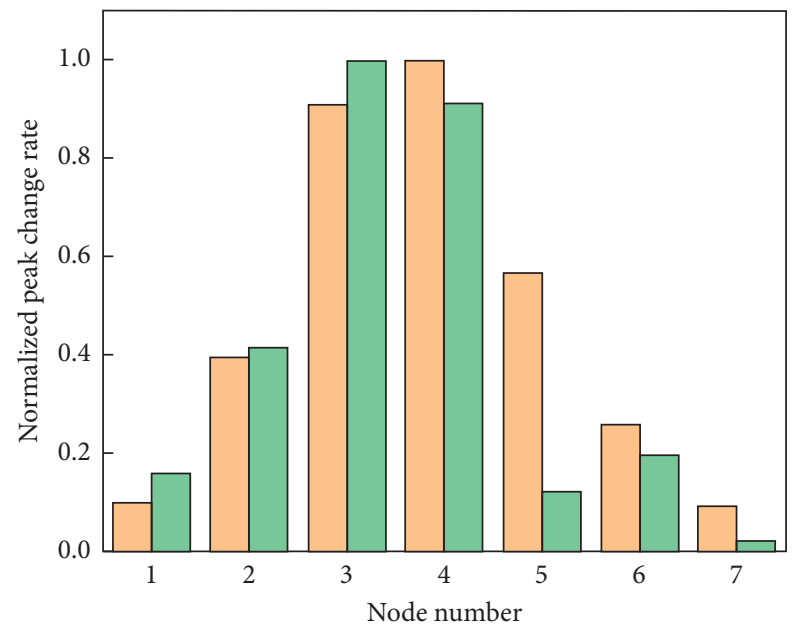

Beam I

$\square$ Beam II

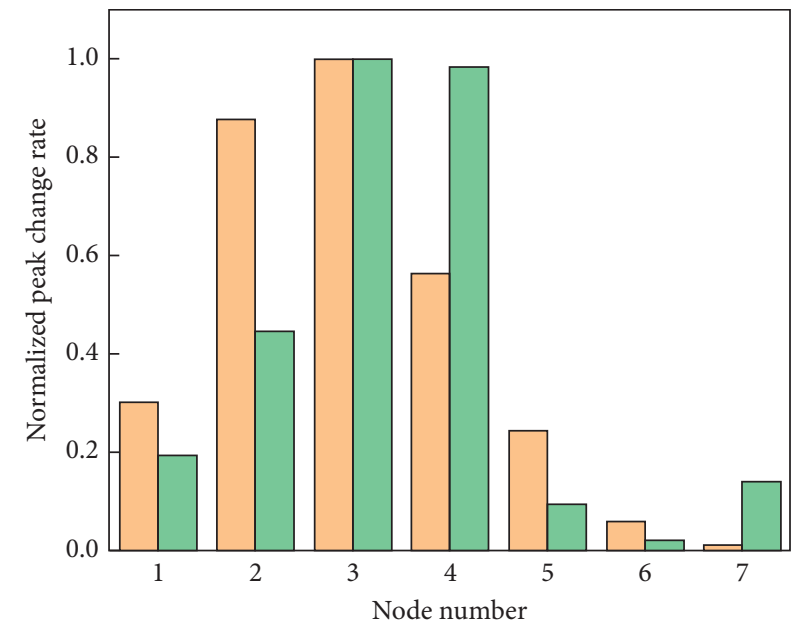

(b)

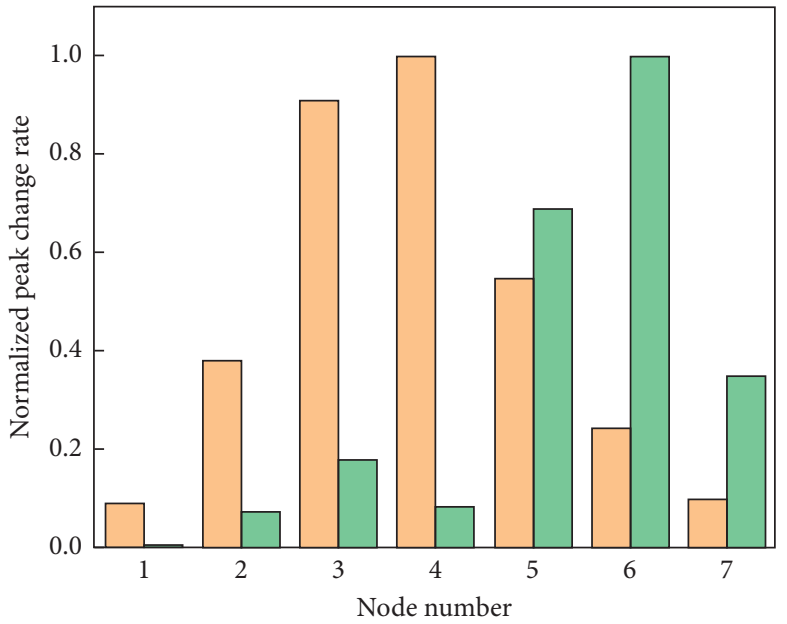

(d)

Figure 9: The peak rate of change under different damage conditions. (a) Elements 230 and 459 damaged simultaneously by $10 \%$, (b) elements 231 and 456 damaged simultaneously by $10 \%$, (c) elements 232 and 456 damaged simultaneously by $10 \%$, and (d) elements 232 and 458 damaged simultaneously by $10 \%$.

largest. For instance, when unit 230 is damaged, the peak rate of change of nodes 800 and 801 at both ends of the element before and after the damage is the maximum; when unit 231 is damaged, the peak rate of change of nodes 801 and 802 of the unit is the maximum. The corresponding relation is also satisfied when other units are damaged separately. Therefore, the damage location on the structure can be determined by the maximum absolute value of the autocorrelation peak rate of change of the dynamic response of each measurement point before and after the damage, that is, the area between two adjacent nodes that has the largest change rate of the autocorrelation peak value corresponds to the damage location of the structure; therefore, the damage location of the structure is realized. 

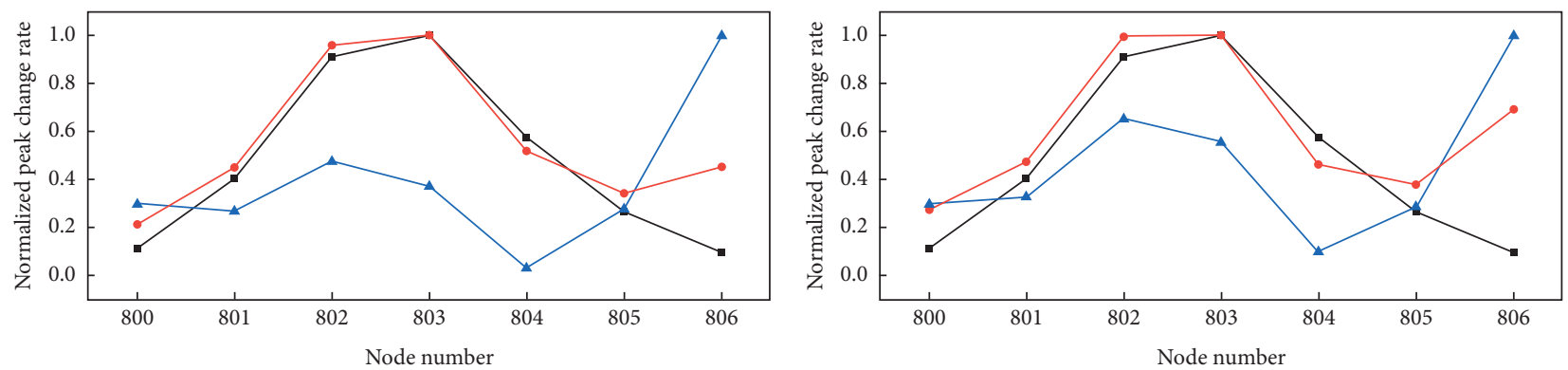

$\rightarrow$ Nonnoise
$\rightarrow \quad \mathrm{SNR}=30 \mathrm{~dB}$

$\rightarrow$ Nonnoise

$\rightarrow \quad \mathrm{SNR}=20 \mathrm{~dB}$

$\rightarrow$ SNR $=15 \mathrm{~dB}$

(a)

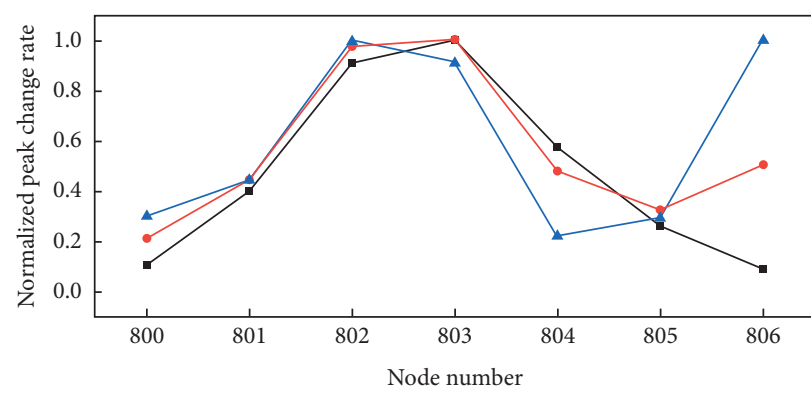

(b)

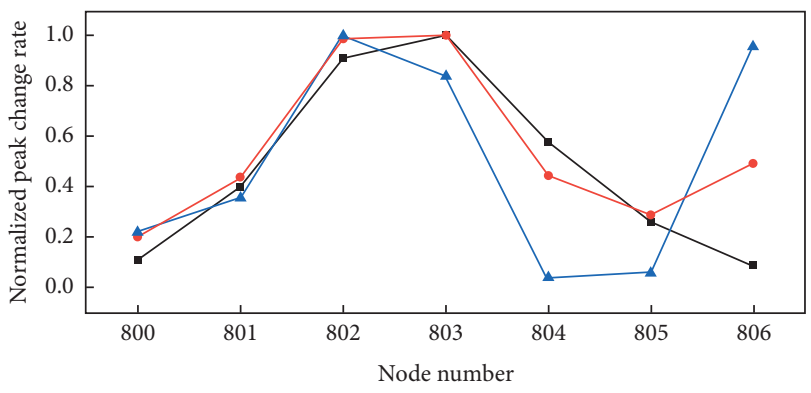

$\longrightarrow$ Nonnoise
$\rightarrow \mathrm{SNR}=15 \mathrm{~dB}$

$\triangle \mathrm{SNR}=10 \mathrm{~dB}$

$$
\begin{aligned}
& \rightarrow \text { Nonnoise } \\
& \rightarrow \mathrm{SNR}=10 \mathrm{~dB} \\
& \rightarrow \mathrm{SNR}=5 \mathrm{~dB}
\end{aligned}
$$

(c)
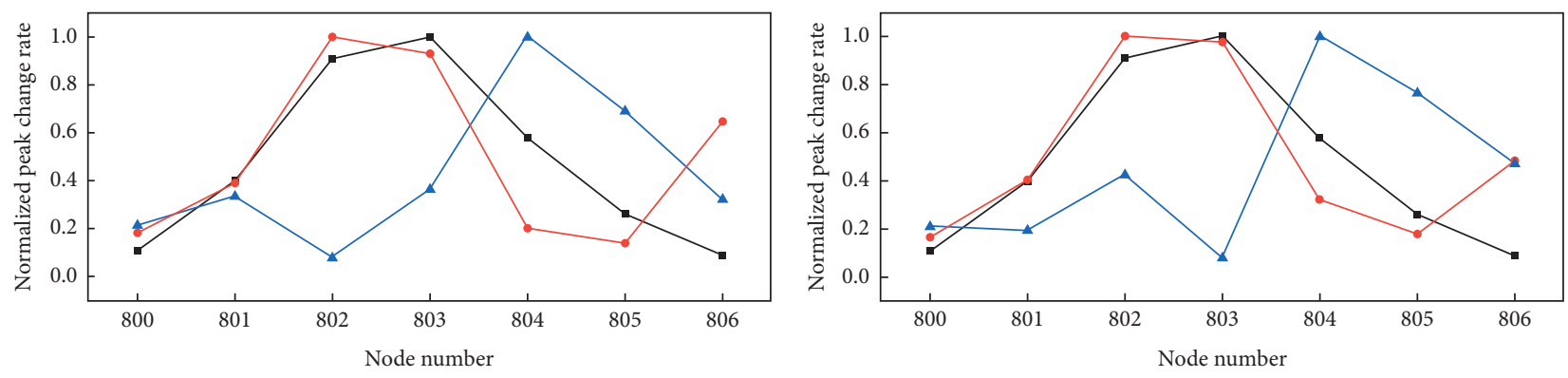

$$
\begin{aligned}
& \longrightarrow \text { Nonnoise } \\
& \rightarrow \mathrm{SNR}=5 \mathrm{~dB} \\
& \longleftarrow \mathrm{SNR}=0 \mathrm{~dB}
\end{aligned}
$$

$$
\begin{aligned}
& \rightarrow \text { Nonnoise } \\
& \rightarrow \mathrm{SNR}=5 \mathrm{~dB} \\
& \longleftarrow \mathrm{SNR}=0 \mathrm{~dB}
\end{aligned}
$$

(e)

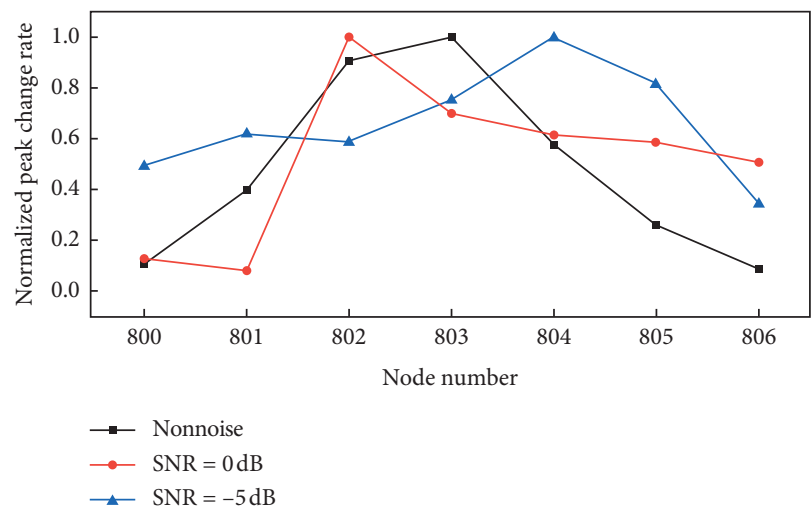

(g)

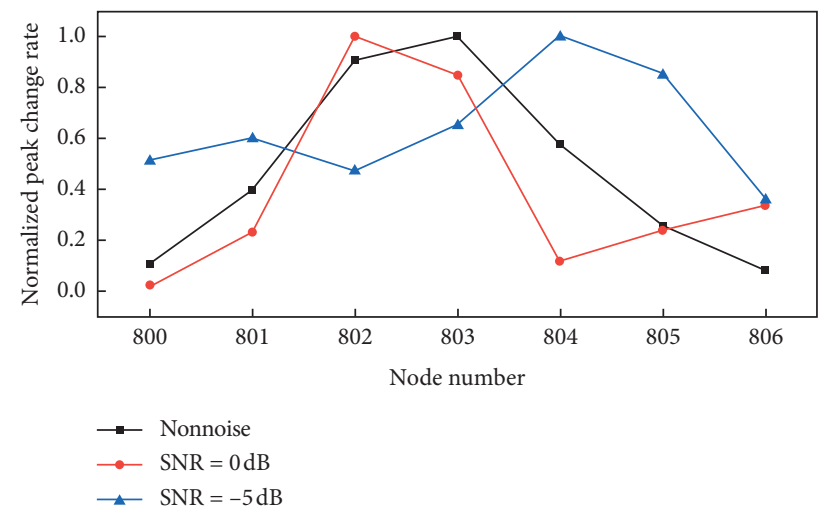

(h)

Figure 10: Antinoise capability of the damage index under different degrees of damage. Element 232 damaged by (a) $5 \%$, (b) $10 \%$, (c) $20 \%$, (d) $30 \%$, (e) $35 \%$, (f) $40 \%$, (g) $45 \%$, and (h) $50 \%$. 
4.3. Double Damage Location Analysis. The middle span beam II of the second floor of the wooden frame was added as the research object. The number of elements of the beam is 454 to 459 , and the corresponding number of nodes is 1,048 to 1,054 . Beams I and II were set to be damaged simultaneously to analyze the effect of the rate of change of the autocorrelation peak value on double damage identification and location of the structure. The different working conditions of the double damage are listed in Table 4.

The peak rate of the autocorrelation of the acceleration response before and after damage under different damage conditions is shown in Figure 9.

It can be observed from the figure that when beams I and II are damaged at the same time, the damage index of the autocorrelation peak rate of the dynamic response before and after damage can also be used to accurately locate the damage and meet the damage location requirements. Therefore, the autocorrelation peak rate of change damage localization index is also effective for double damage.

4.4. Antinoise Interference Capability of Damage Index. Taking element 232 of beam I as an example to simulate the influence of noise on the damage location index in practical engineering, the degrees of damage are 5\%, $10 \%, 20 \%, 30 \%$, $35 \%, 40 \%$, and $45 \%$. White Gaussian noise with different noise levels was added to the nodal acceleration. The antinoise interference capability of the damage index under different degrees of damage was calculated, and the results are shown in Figure 10.

It can be observed from Figure 10(a) that when element 232 is damaged by $5 \%$ (in the case of no noise), the two adjacent nodes with the highest autocorrelation peak change rate before and after structural damage are 802 and 803 , which are also the two nodes at both ends of unit 232. This shows that the damage localization index constructed by the autocorrelation peak change rate can accurately identify early damage to the structure and has good capability in terms of damage identification and localization. At a signalto-noise ratio (SNR) of $30 \mathrm{~dB}$, the damage index can still accurately locate the structure and is not affected by measurement noise. However, when $\mathrm{SNR}=20 \mathrm{~dB}$, node 806 has the maximum peak change rate and is affected by noise, which does not meet the requirements of the structural damage location.

When the unit damage is $10 \%$ and $\mathrm{SNR}=20 \mathrm{~dB}$, the two adjacent nodes with the highest peak change rates are 802 and 803 , indicating that the damage location index is not affected by measurement noise, and the damage location can still be accurately identified. It can be observed from Figures $10(\mathrm{a})$ to $10(\mathrm{~g})$ that the antinoise interference capability of the damage location index gradually improved with an increase in the degree of damage. When the unit damage is $45 \%$, it can still meet the requirements of the damage location under the condition of $\mathrm{SNR}=0 \mathrm{~dB}$, and accurate positioning is also possible. However, when the degree of damage is $50 \%$, the antinoise capability of the damage location index remains stable at $\mathrm{SNR}=0 \mathrm{~dB}$, indicating that the antinoise capability of the damage location index of the autocorrelation peak change rate tends to be stable at $50 \%$ degree of damage.

Therefore, for structures subjected to random vibration, the change rate of the peak value of the autocorrelation function at each measurement point before and after damage was used as the damage location index owing to its good antinoise interference capability.

\section{Conclusion}

In this study, the peak change rate of the autocorrelation function of the dynamic response before and after damage was used as the damage index to locate the damage to the Xi'an Bell Tower by reducing the stiffness of each element to simulate the damage to the structure. The results show that

(1) The peak value vector of the autocorrelation function of the dynamic response of the intact structure under random vibration has a fixed shape, which can be used as the basis for structural damage identification and location.

(2) The rate of change of the peak value of the autocorrelation function of the acceleration dynamic response to each measurement point before and after the structural damage was calculated. The two adjacent measurement points with the highest degree of change corresponded to two nodes at both ends of the damage unit, indicating that using the rate of change of the autocorrelation peak value as the damage location index could accurately determine the damage location of the structure.

(3) The antinoise capability of the damage location index gradually improved with an increase in the degree of damage. When the degree of damage of the structure is $45 \%$, the damage location index can still accurately determine the damage location of the structure if the SNR is $0 \mathrm{~dB}$, and the damage location index is not affected by measurement noise. At 50\% degree of damage, the antinoise capability of the positioning index tended to be stable.

Therefore, the autocorrelation peak change rate of the dynamic response before and after damage was used as the damage location index, which can accurately determine the damage location of the structure and has good antinoise capability. However, one limitation of the method proposed in this study is that it requires many measurement points; therefore, optimizing the location and number of measurement points is a future research direction.

\section{Data Availability}

All data analyzed during this study are included in this article.

\section{Conflicts of Interest}

The authors declare that they have no conflicts of interest. 


\section{Acknowledgments}

The authors of this study gratefully acknowledge the funding support received from the National Natural Science Foundation of China (grant no. 52068063), Key Project of Shaanxi Provincial Natural Science Basic Research Program (grant no. 2018JZ5002), Research Project of Gansu Provincial Department of Housing and Urban-Rural Development (grant no. JK2019-11), Gansu Province Higher Education Innovation Fund Project (grant no. 2020B-173), and Key Project of Shaanxi Polytechnic Institute (grant no. 2020YKZD-003).

\section{References}

[1] Q. L. Li, Through the Wall: Section View of Chinese Classic Ancient Architecture, Guangxi Normal University Press, Guilin, China, 2009, in Chinese.

[2] J. Wang and Q. S. Yang, "Numerical simulation of damage identification for Tibetan ancient timber structure," Journal of Vibration, Measurement \& Diagnosis, vol. 34, no. 1, pp. 160-167, 2014.

[3] X. Wang, W. B. Hu, and G. S. Han, "Structural damage alarming for ancient wood frame structure based on wavelet packet energy spectrum," Industrial Construction, vol. 43, no. 8, pp. 24-28, 2013.

[4] X. Wang, W. B. Hu, and Z. B. Meng, "Damage detection of an ancient wood structure based on wavelet packet energy curvature difference," Journal of Vibration and Shock, vol. 33, no. 7, pp. 153-159, 2014.

[5] X. Wang and Z. B. Meng, "Damage detection of wood structure for Xi'an bell tower under ground transportation incentive," Building Structure, vol. 47, no. 17, pp. 82-87, 2017.

[6] X. Wang, Z. B. Meng, and Z. C. Liang, "Damaged identification of Xi'an bell tower wood structures based on wavelet packet energy spectrum," Chinese Journal of Applied Mechanics, vol. 37, no. 3, pp. 1245-1252, 2020.

[7] J. X. Fan, Research on the Structural Damage Identification Method Based on Stochastic Resonance, Xi'an University of Architecture and Technology, Xi'an, China, 2018.

[8] F. C. Choi, J. Li, B. Samali, and K. Crews, "Application of modal-based damage-detection method to locate and evaluate damage in timber beams," Journal of Wood Science, vol. 53, no. 5, pp. 394-400, 2007.

[9] C. Hu and M. T. Afzal, "A statistical algorithm for comparing mode shapes of vibration testing before and after damage in timbers," Journal of Wood Science, vol. 52, no. 4, pp. 348-352, 2006.

[10] M. J. Khosraviani, O. Bahar, and S. H. Ghasemi, "Global and local damage detection in continuous bridge decks using instantaneous amplitude energy and cross-correlation function methods," KSCE Journal of Civil Engineering, vol. 25, no. 2, pp. 603-620, 2021.

[11] M. Morgantini and R. Betti, "The inner product vector as an output-only cross-correlation-based feature to structural damage assessment," Journal of Vibroengineering, vol. 22, no. 6, pp. 1373-1398, 2020.

[12] W. Li and Y. Huang, "A method for damage detection of a jacket platform under random wave excitations using cross correlation analysis and PCA-based method," Ocean Engineering, vol. 214, Article ID 107734, 2020.

[13] M. Li, W.-X. Ren, T.-L. Huang, and N.-B. Wang, "Experimental investigations on the cross-correlation function amplitude vector of the dynamic strain under varying environmental temperature for structural damage detection," Journal of Low Frequency Noise, Vibration and Active Control, vol. 39, no. 3, pp. 631-649, 2020.

[14] T. K. Lin and H. Fajri, "Damage detection of structures with detrended fluctuation and detrended cross-correlation analyses," Smart Materials and Structures, vol. 26, no. 3, Article ID 035027, 2017.

[15] L. S. Huo, X. Li, Y. B. Yang, and H. N. Li, "Damage detection of structures for ambient loading based on cross correlation function amplitude and SVM," Shock and Vibration, vol. 2016, Article ID 3989743, 12 pages, 2016.

[16] M. Y. Zhang, R. Schmidt, and B. Markert, "Structural damage detection using auto correlation functions of vibration response under sinusoidal excitation," Journal of Physics: Conference Series, vol. 628, no. 1, Article ID 012029, 2015.

[17] M. Zhang and R. Schmidt, "Study on an auto-correlationfunction-based damage index: Sensitivity analysis and structural damage detection," Journal of Sound and Vibration, vol. 359, pp. 195-214, 2015.

[18] M. Zhang and R. Schmidt, "Sensitivity analysis of an autocorrelation-function-based damage index and its application in structural damage detection," Journal of Sound and Vibration, vol. 333, no. 26, pp. 7352-7363, 2014.

[19] Y. F. Hou, Damage Detection of Historic Timber Structure under Random Excitation Based on Cross Correlation Function Amplitude Vectors, Xi'an University of Architecture and Technology, Xi'an, China, 2012.

[20] Y. Wei, The Damage Identification of Wooden Beam Cracks from Ancient Building, Beijing University of Civil Engineering and Architecture, Beijing, China, 2017.

[21] Y. S. Huang, Study on Damage Detection and Health Monitoring of Wooden Structure Based on Piezoceramic Transducer Enabled Active Sensing, Yangtze University, Jingzhou, China, 2019.

[22] B. Z. Zhuang, An introduction to Random Vibration, Science Press, Beijing, China, 1981, in Chinese.

[23] B. Z. Zhuang, Random Vibration of Structure, National Defense Industry Press, Beijing, China, 1995, in Chinese.

[24] J. S. Pan, L. Wang, and P. Yan, Analysis and Application of Random Signal, Tsinghua University Press, Beijing, China, 2011, in Chinese.

[25] Q. F. Xie, L. Wang, L. P. Zhang, W. B. Hu, and C. Y. Qian, "Shaking table tests on wooden structure model of Xi' an bell tower," Journal of Building Structures, vol. 39, no. 12, pp. 128-138, 2018.

[26] X. G. Zhao, Aseismic Performance Analysis of Xi'an Bell Tower in FEM, Xi'an University of Architecture and Technology, Xi'an, China, 2008.

[27] Z. B. Meng, Analysis and Assessment of the Vibration Responds Traffic-Induced of Xi'an Bell Tower, Xi'an University of Architecture and Technology, Xi'an, China, 2009.

[28] M. H. Yu, X. B. Zhang, and D. P. Fang, Research on the City Wall in Xi'an-Structure and Earthquake-Proof, Xi'an Jiaotong University Press, Xi'an, China, 1994, in Chinese.

[29] D. P. Fang, M. H. Yu, Y. Miyamoto, S. Iwasaki, and H. Hikosaka, "Experimental studies on structural characteristics of ancient timber architectures," Engineering Mechanics, vol. 17, no. 2, pp. 75-83, 2000.

[30] D. P. Fang, M. H. Yu, Y. Miyamoto, S. Iwasaki, and H. Hikosaka, "Numerical analysis on structural characteristic of ancient timber architecture," Engineering Mechanics, vol. 18, no. 1, pp. 137-144, 2001. 
[31] M. H. Yu, X. D. Liu, D. P. Fang, and X. B. Zhang, "An experiment study of static and dynamic characteristics on the front tower over the ancient Xi'an city wall," Journal of Jiaotong University, vol. 25, no. 3, pp. 55-62, 1991.

[32] J. H. Zhao, M. H. Yu, S. Y. Yang, and J. J. Sun, "Dynamic analysis for the ancient superstructure of the east city gate of Xi'an by FEM," China Civil Engineering Journal, vol. 33, no. 1, pp. 32-35, 2000.

[33] J. H. Zhao, M. H. Yu, D. F. Gao, and J. J. Sun, "FEM analysis on the elasto-plasticity of ancient wooden structure," Journal of Xi'an University of Architecture \& Technology (Natural Science Edition), vol. 31, no. 2, pp. 3-5, 1999.

[34] K. Yao, H. T. Zhao, and H.P. Ge, "Experimental studies on the characteristic of mortise-tenon joint in historic timber buildings," Engineering Mechanics, vol. 23, no. 10, pp. 168173, 2006.

[35] G. S. Han, The Micro Vibration of Urban Rail Transit Impact on Ancient Building, Xi'an University of Architecture and Technology, Xi'an, China, 2011. 